\title{
Identification of inhibitors of ovarian cancer stem-like cells by high-throughput screening
}

\author{
Roman Mezencev, Lijuan Wang and John F McDonald ${ }^{*}$
}

\begin{abstract}
Background: Ovarian cancer stem cells are characterized by self-renewal capacity, ability to differentiate into distinct lineages, as well as higher invasiveness and resistance to many anticancer agents. Since they may be responsible for the recurrence of ovarian cancer after initial response to chemotherapy, development of new therapies targeting this special cellular subpopulation embedded within bulk ovarian cancers is warranted.

Methods: A high-throughput screening (HTS) campaign was performed with 825 compounds from the Mechanistic Set chemical library [Developmental Therapeutics Program (DTP)/National Cancer Institute (NCI)] against ovarian cancer stem-like cells (CSC) using a resazurin-based cell cytotoxicity assay. Identified sets of active compounds were projected onto self-organizing maps to identify their putative cellular response groups.
\end{abstract}

Results: From 793 screening compounds with evaluable data, 158 were found to have significant inhibitory effects on ovarian CSC. Computational analysis indicates that the majority of these compounds are associated with mitotic cellular responses.

Conclusions: Our HTS has uncovered a number of candidate compounds that may, after further testing, prove effective in targeting both ovarian CSC and their more differentiated progeny.

Keywords: High-throughput screening, Ovarian cancer, Cancer stem cells

\section{Background}

Ovarian cancer is the most lethal of gynecological cancers [1] despite its typically high initial response rate to chemotherapy [2]. Recent evidence supports the existence of ovarian cancer stem-like cells (CSC), characterized by self-renewal capacity, ability to differentiate into distinct lineages, high invasiveness and resistance to a number of anticancer agents [3-6]. Since CSC have been shown to be resistant to most current chemotherapies, the frequent recurrence of ovarian cancer is believed, at least in part, to be attributable to the existence of chemo-resistant sub-populations of cancer cells embedded within bulk tumors [6]. For this reason, there is considerable current interest in the development of new chemotherapies that can effectively target this insidious subpopulation of tumor cells [7].

Thus far, searches for compounds that may be therapeutically effective against CSC have employed two

\footnotetext{
* Correspondence: john.mcdonald@biology.gatech.edu

School of Biology and Integrated Cancer Research Center, Georgia Institute of Technology, 310 Ferst Dr, Atlanta, GA 30332, USA
}

alternative strategies. One approach has been to evaluate molecules known to be inhibitory against pathways believed to be deregulated in CSC (e.g., the Hedgehog, $\mathrm{NOTCH}, \mathrm{PTEN} / \mathrm{AKT}$ and $\mathrm{WNT} / \beta$-catenin signaling pathways) [8]. This approach has resulted in the identification of several potential therapeutic agents that are currently in clinical trials [9]. A second approach is the high-throughput screening (HTS) of CSC-enriched cell populations with libraries of potential inhibitory compounds. This approach has been productively employed to identify candidate compounds displaying cytotoxic/ inhibitory effects on breast cancer [10] and glioma $[11,12]$ CSC.

We have recently reported the isolation and characterization of ovarian CSC from an established ovarian cancer cell line OVCAR-3 [13]. These cells display a variety of features and molecular profiles characteristic of CSC previously isolated from ovarian and other cancer tissues [14-17]. Here we report the results of a high-throughput screening of 825 potential drugs (the National Cancer Institute's "Mechanistic Set" library) 
$[18,19]$ against ovarian CSC and the subsequent identification of compounds that display significant potential for future development as ovarian CSC therapeutic agents.

\section{Methods \\ Cells}

Spheroids were derived from OVCAR-3 cell line as previously described [13] and grown in the stem cell medium (SCM): DMEM/F12 (1:1) supplemented with $0.4 \%$ bovine serum albumin (BSA, Sigma-Aldrich, Inc. St. Louis, MO), $20 \mathrm{ng} / \mathrm{mL}$ epidermal growth factor (EGF, Invitrogen Corporation, Carlsbad, CA), $10 \mathrm{ng} / \mathrm{mL}$ basic fibroblast growth factor (bFGF, Sigma-Aldrich), $5 \mu \mathrm{g} / \mathrm{mL}$ insulin (Sigma-Aldrich) and 1\% antibiotic-antimycotic solution (Mediatech-Cellgro, Manassas, VA) in $100 \mathrm{~mm}$ ultra-low attachment Petri dishes (Corning Incorporated, Corning, NY). Spheroids grown under these conditions were dissociated weekly using 0.05\% trypsin-0.02\% EDTA solution (Lonza, Walkerswille, MD) and sub-cultured until the amount of cells was adequate for HTS.

\section{Compounds}

The NCI Mechanistic Set was provided by the Developmental Therapeutic Program (NCI/NIH) as a set of 825 compounds plated in eleven 96-well plates (plate numbers: 4520-4530; suffix: 69). Basic information on these compounds can be retrieved from the DTP website [20] using plate number as the search parameter. These compounds were selected from 37,836 compounds in the NCI repository to represent a broad range of growth inhibition patterns in the NCI 60 cell line screen $[18,19]$ and consequently, they likely represent a diversity of the modes of action of these compounds. Compounds were supplied by DTP as $1 \mathrm{mM}$ solutions in DMSO.

\section{HTS and data analysis}

Spheroids were dissociated to single cells using trypsin; trypsin was neutralized using Soybean Trypsin Inhibitor (Life Technologies, Grand Island, NY; Catalogue \# 17075029), and cells were re-suspended in SCM to a density of 50,000 cells $/ \mathrm{mL}$. Cells were plated into flat bottom ultra-low attachment 96 well plates (Corning, Product \#3474) in a volume of $198 \mu \mathrm{L}$ per well $(200 \mu \mathrm{L}$ of SCM for blank wells) and incubated for $24 \mathrm{~h}$ at $37^{\circ} \mathrm{C}$ and humidified atmosphere with $5 \% \mathrm{CO}_{2}$. Drug dilutions were prepared as follows: the eleven supplied NCI Mechanistic Set plates were copied ( $4 \mu \mathrm{L}$ of DMSO solution per well) into sterile, round bottom polypropylene 96-well plates (Corning, Product \#3359) and each drug was diluted with $22 \mu \mathrm{L}$ media (working concentrations $153.8 \mu \mathrm{M}) .3 \mu \mathrm{L}$ of diluted library were added to $198 \mu \mathrm{L}$ of cells (4 replicated wells for each drug), which resulted in final drug concentration of $2.29 \mu \mathrm{M}$. The plates were incubated for $96 \mathrm{~h}$ at $37^{\circ} \mathrm{C}$ and humidified atmosphere with $5 \% \mathrm{CO}_{2}$. Thereafter, $20 \mu \mathrm{L}$ of TOX8 reagent (Sigma-Aldrich) were added to each well and after 4-h incubation fluorescence intensities were measured for each well at $560 \mathrm{~nm}$ (excitation) and $590 \mathrm{~nm}$ (emission). The resazurin (Alamar blue)-based TOX8 reagent has been previously established as a reliable method for determining cell viability/cytotoxicity of tumor spheroid cell cultures [21,22].

Fluorescence intensities for replicated wells were analyzed using Grubb's test for detecting outliers at critical $\mathrm{Z}=1.48$ and outliers were removed from the dataset (test was applied only once for each replicated set of values). Percent growth of treated cells relative to untreated control cells was calculated from fluorescence intensities using the formula: \%growth $=100 \times$ [(average for treated cells - average for blank wells)]/ [(average for untreated cells) -(average for blank wells)]

Other parameters recommended by Inglese et al. [23], HTS plate design, assay performance evaluation and systematic error detection are presented in Additional file 1.

Of the 793 compounds that passed our assay performance standard, 99 displayed a single outlier among 4 replicated fluorescence intensity values and these outliers were removed before \% growth values were calculated.

Statistical significance of differences between fluorescence intensities of drug-treated and untreated control wells was evaluated using Welch's $t$-test followed by Holm's step-down method for multiplicity adjustment [24]. Two-sided p-values were determined by Welch's $t$-test from raw fluorescence intensities corresponding to replicated treated and untreated control wells. These p-values represent probabilities that the difference between mean signal intensities for treated and control wells were obtained by chance. Holm's procedure was applied to 793 p-values (compounds that passed assay performance test) to counteract the problem of multiple comparisons and to ascertain that the probability of falsely identifying one or more compounds as significantly affecting growth of ovarian cancer stem-like cells is not more than $10 \%$. Thus, compounds selected by controlling for family-wise error rate (FWER) of 0.10 were classified as compounds with statistically significant effect on growth of ovarian cancer stem-like cells. Drugs with \% growth $80-110 \%$ were considered as compounds with no effect on growth of ovarian cancer stem-like cells.

Results of HTS were interpreted (i) in the context of the activity of FDA-approved drugs present in the library; (ii) in comparison with the potencies of screened compounds against OVCAR-3 cell line (parental cells from which CSC were isolated), and (iii) via mapping to self-organizing maps (SOMs).

A list of 97 FDA-approved oncology drugs was built from the data on the Approved Oncology Drug Set 
accessible at the DTP website [25] and made available in Additional file 2.

Potencies of library compounds against OVCAR-3 cell line (Dec 2010 release) were retrieved from the DTP website [26]. If multiple $\mathrm{GI}_{50}$ values were available for the same compound, the average was taken without inclusion of default values (Note: NCI does not provide descriptive statistics (SD or SEM) for the determined $\mathrm{GI}_{50}$ values for tested cells).

All 793 library compounds that passed our assay performance criteria and selected subsets of compounds active against CSC were mapped onto SOMs using the web-based tool 3D MIND developed by the Covell group at the National Cancer Institute [27]. The SOM method represents a type of artificial neural network trained using unsupervised learning to cluster high dimensional data and project them into a low dimensional space. SOMs used in this work was generated from $\mathrm{GI}_{50}$ values for $\sim 30,000$ compounds across 60 cell lines and consists of 1,350 hexagonal clusters with 9 major cellular response categories: mitosis $(\mathrm{M})$, membrane function $(\mathrm{N})$, nucleic acid metabolism (S), metabolic stress and cell survival (Q), kinases/phosphatases and oxidative stress (P) and 4 unexplored regions (RFJV) [28]. The significance of differences in the distribution of CSC active subsets and all library compounds to these areas was evaluated using Fisher's exact test with Yate's continuity correction and the difference was considered significant for two-sided $\mathrm{p}$-value $<0.01$.

\section{Determination of $\mathrm{Gl}_{50}$}

$\mathrm{GI}_{50}$ values (concentrations of tested agents that inhibited growth of CSC cell cultures after 96-h incubation to $50 \%$ of the untreated control) were determined for 5 compounds (NSC72961, NSC302979, NSC82116, NSC673622 and NSC243928) randomly selected from those resulting in $\leq 50 \%$ cellular growth relative to untreated controls. $\mathrm{GI}_{50}$ values were determined from concentration-response data generated by the same assay and cell system as used in our HTS. For each compound, 5 concentrations were used $(15.6 \mathrm{nM}, 62.5$ $\mathrm{nM}, 250 \mathrm{nM}, 1000 \mathrm{nM}$ and 4,000 nM). Percent growth (control based normalization) was calculated as described in (Additional file 1: Table $\mathrm{S} 1$ ) and $\mathrm{GI}_{50}$ values were determined by non-linear regression of logtransformed data using a normalized response-variable slope model (GraphPad Prism 5.01; GraphPad Software, Inc.) and expressed as mean \pm SEM.

\section{Results and discussion}

HTS identified over 100 compounds that significantly inhibit ovarian CSC growth

NCI's Developmental Therapeutics Program (DTP) maintains a repository of synthetic and naturally occurring potential anticancer drugs. A sub-set of these compounds, termed the "Mechanistic Set", represents the range of distinct growth inhibition patterns observed when the repository compounds were tested against the NCI-60 panel of cancer cell lines $[18,19]$.

The CSC culture used in this study was derived from OVCAR-3 cells and is composed of tumor spheroids enriched with slowly proliferating self renewing stem-like cells that have been previously demonstrated to resist apoptosis after detachment from the surface (anoikis), a property known to be prerequisite for invasion and metastasis [13]. In addition, these cells have been shown to display significantly higher invasiveness, migration potential, and resistance to standard anticancer agents relative to the parental OVCAR- 3 cells, as well as an ability to differentiate from a CD44-positive/ mesenchymal-like phenotype to CD44-negative/epithelial like phenotype [13].

CSC were seeded in 96-well plates and allowed to proliferate for $24 \mathrm{~h}$ prior to exposure to the 825 compounds comprising the NCI Mechanistic Set of experimental compounds (chemical library). After $96 \mathrm{~h}$ of exposure, \% growth of treated cells relative to untreated controls was determined. To reduce the possibility of spurious results, we conducted an assay performance test and subsequently excluded 32 compounds from our survey that were associated with unreliable results (Additional file 3). Of the remaining 793 compounds (Additional file 4), $329(41.5 \%)$ did not display an appreciable effect on ovarian CSC growth (80-110\% growth), while 161 compounds $(20.3 \%)$ displayed a statistically significant effect at FWER $=0.10$ with 158 compounds displaying an inhibiting effect (3.3-74.1\% growth) and 3 compounds displaying a stimulatory effect (135.6-158.7\% growth).

In order to focus on the most inhibitory compounds, we operationally defined CSC inhibitory compounds as those displaying a $\leq 50 \%$ cell growth relative to untreated controls. Based on these criteria, 136 of the 793 compounds $(17.2 \%)$ were classified as inhibitory (range of inhibitory growth: 3.3-50.4\%) (Table 1). These 136 inhibitory compounds are listed in Table 1 by a NCI compound number (NSC). A full list the various names associated with each NCI compound number is available as an ASCII file at the National Cancer Institute's Developmental Therapeutics Program website [29].

We randomly selected 5 of the 136 inhibitory compounds for confirmatory testing. In each case, the determined $\mathrm{GI}_{50}$ values were indicative of a significant inhibitory effect: NSC72961: 104.2 $\pm 13.54 \mathrm{nM}$; NSC302979:

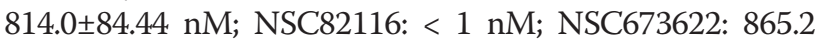
nM (SEM not determined); NSC243928: 831.6 $\pm 134.72 \mathrm{nM}$ (Figure 1). The cellular phenotype of CSC after treatment with inhibitory compounds is consistent with cell death/apoptosis (Figure 2). 
Table 1 List of 136 CSC-inhibitory compounds identified by HTS (\%growth $\leq 50 \%$, p-adj. $\leq 0.1$ ) compared to $\mathrm{Gl}_{50}$ of OVCAR-3 cells

\begin{tabular}{|c|c|c|c|c|c|c|c|c|c|c|c|}
\hline & \multicolumn{6}{|c|}{ rove } \\
\hline NSC & \%growth & SD & p-value & $\begin{array}{l}\text { p-adj } \\
\text { (Holms) }\end{array}$ & $\begin{array}{l}\mathrm{Gl}_{50}(-\log 10) \\
\text { OVCAR-3 }\end{array}$ & 260610 & 13.9 & 5.5 & 2.48E-06 & 1.77E-03 & 6.79 \\
\hline 618332 & 3.3 & 4.0 & 3.73E-07 & $2.78 \mathrm{E}-04$ & 5.08 & 631529 & 14.5 & 3.2 & 4.08E-07 & 3.04E-04 & 5.82 \\
\hline 219734 & 4.2 & 2.0 & $9.47 \mathrm{E}-07$ & $6.88 \mathrm{E}-04$ & 6.43 & 85236 & 14.5 & 2.5 & 8.67E-08 & 6.61E-05 & 5.82 \\
\hline 128305 & 4.9 & 3.4 & $8.02 \mathrm{E}-06$ & 5.59E-03 & 4.34 & 376265 & 14.7 & 7.5 & $1.41 \mathrm{E}-05$ & $9.53 \mathrm{E}-03$ & 8.50 \\
\hline 168597 & 5.1 & 5.5 & $2.42 \mathrm{E}-06$ & 1.73E-03 & 7.69 & 349644 & 14.9 & 4.6 & 2.95E-05 & 1.95E-02 & 7.72 \\
\hline 328426 & 5.3 & 3.2 & 4.64E-07 & $3.44 \mathrm{E}-04$ & 7.62 & 89671 & 15.0 & 2.5 & $6.73 \mathrm{E}-07$ & 4.95E-04 & 7.55 \\
\hline 143648 & 5.6 & 2.3 & 1.64E-07 & $1.23 \mathrm{E}-04$ & 7.43 & 105808 & 15.3 & 3.8 & 1.15E-05 & 7.87E-03 & 5.96 \\
\hline 165563 & 6.1 & 4.4 & $3.58 \mathrm{E}-07$ & 2.67E-04 & 8.05 & 635121 & 16.0 & 5.3 & $9.44 \mathrm{E}-06$ & $6.53 \mathrm{E}-03$ & 5.52 \\
\hline 145366 & 7.1 & 2.1 & $5.21 \mathrm{E}-08$ & 4.00E-05 & 5.75 & 93419 & 17.1 & 7.4 & 2.92E-05 & $1.93 \mathrm{E}-02$ & 6.13 \\
\hline 636132 & 7.3 & 3.2 & $9.47 \mathrm{E}-07$ & $6.89 \mathrm{E}-04$ & 4.00 & 268251 & 17.4 & 6.2 & 2.99E-06 & 2.12E-03 & 8.96 \\
\hline 323241 & 7.7 & 2.4 & $1.59 \mathrm{E}-07$ & $1.20 \mathrm{E}-04$ & 7.54 & 202000 & 17.7 & 5.0 & 3.03E-09 & 2.38E-06 & 4.05 \\
\hline 622732 & 8.0 & 4.9 & 4.93E-06 & $3.46 \mathrm{E}-03$ & 4.90 & 659999 & 18.0 & 6.4 & 1.30E-08 & $1.01 \mathrm{E}-05$ & 5.99 \\
\hline 208913 & 8.0 & 3.5 & 8.17E-07 & 5.96E-04 & 3.80 & 172924 & 18.5 & 3.1 & 7.81E-08 & 5.97E-05 & 6.67 \\
\hline 306864 & 8.0 & 3.1 & $3.86 \mathrm{E}-07$ & $2.88 \mathrm{E}-04$ & 5.76 & 673622 & 18.5 & 9.1 & 1.83E-05 & 1.23E-02 & 6.59 \\
\hline 4320 & 8.0 & 3.3 & $6.94 \mathrm{E}-08$ & 5.31E-05 & 9.56 & 146604 & 19.2 & 4.6 & 2.41E-09 & 1.90E-06 & 6.65 \\
\hline 3053 & 8.4 & 3.9 & 1.38E-08 & $1.07 \mathrm{E}-05$ & 8.54 & 349156 & 19.5 & 2.6 & 1.73E-06 & $1.24 \mathrm{E}-03$ & 6.92 \\
\hline 265450 & 8.5 & 3.2 & $8.14 \mathrm{E}-08$ & $6.21 \mathrm{E}-05$ & 7.20 & 526417 & 19.7 & 3.8 & 5.38E-08 & 4.13E-05 & 9.28 \\
\hline 354844 & 8.6 & 6.0 & 4.34E-07 & $3.22 \mathrm{E}-04$ & 7.26 & 400978 & 20.3 & 2.4 & 7.26E-09 & 5.67E-06 & 7.97 \\
\hline 164914 & 8.8 & 3.7 & 2.95E-09 & $2.32 \mathrm{E}-06$ & 6.75 & 24817 & 20.4 & 5.8 & 2.23E-08 & $1.72 \mathrm{E}-05$ & 7.67 \\
\hline 63701 & 8.9 & 3.4 & 1.00E-09 & 7.88E-07 & 7.46 & 319726 & 20.6 & 4.0 & 5.30E-09 & 4.15E-06 & 8.00 \\
\hline 697726 & 9.0 & 3.5 & 5.32E-09 & 4.16E-06 & 7.56 & 614826 & 20.8 & 5.2 & 1.41E-05 & 9.52E-03 & 6.66 \\
\hline 637578 & 9.1 & 2.3 & $1.04 \mathrm{E}-07$ & 7.87E-05 & 8.36 & 679524 & 20.9 & 3.5 & $1.94 \mathrm{E}-10$ & 1.54E-07 & 7.50 \\
\hline 614928 & 9.3 & 2.0 & 7.60E-07 & $5.56 \mathrm{E}-04$ & 4.51 & 629301 & 20.9 & 5.5 & 2.23E-05 & 1.49E-02 & 4.80 \\
\hline 667467 & 9.8 & 3.9 & 3.53E-10 & 2.79E-07 & 4.00 & 129414 & 21.1 & 7.4 & 5.48E-05 & 3.58E-02 & 7.41 \\
\hline 65937 & 10.2 & 2.1 & $1.08 \mathrm{E}-07$ & $8.16 \mathrm{E}-05$ & - & 337766 & 21.4 & 5.8 & $1.20 \mathrm{E}-08$ & 9.34E-06 & 6.73 \\
\hline 65423 & 10.4 & 3.1 & $2.61 \mathrm{E}-10$ & 2.06E-07 & 5.78 & 7532 & 21.7 & 8.3 & $3.12 \mathrm{E}-06$ & $2.21 \mathrm{E}-03$ & 8.00 \\
\hline 690634 & 10.8 & 2.9 & $7.52 \mathrm{E}-07$ & $5.51 \mathrm{E}-04$ & 7.59 & 172946 & 21.7 & 5.6 & $1.25 \mathrm{E}-05$ & 8.50E-03 & 7.46 \\
\hline 24559 & 10.8 & 3.6 & $9.91 \mathrm{E}-11$ & 7.86E-08 & 7.35 & 328587 & 22.1 & 4.6 & 2.91E-09 & 2.29E-06 & 5.77 \\
\hline 18268 & 10.9 & 3.4 & $2.24 \mathrm{E}-08$ & $1.73 \mathrm{E}-05$ & 8.41 & 34391 & 22.2 & 4.2 & 4.20E-07 & $3.12 \mathrm{E}-04$ & 5.60 \\
\hline 243023 & 11.0 & 3.4 & 4.48E-06 & 3.15E-03 & 8.07 & 153858 & 22.5 & 4.8 & $9.62 \mathrm{E}-07$ & 6.97E-04 & 9.48 \\
\hline 635448 & 11.1 & 5.9 & 1.19E-08 & $9.27 \mathrm{E}-06$ & 7.69 & 625483 & 22.8 & 9.7 & 2.53E-05 & 1.68E-02 & 4.66 \\
\hline 7525 & 11.3 & 2.4 & 4.99E-06 & 3.49E-03 & 7.60 & 82116 & 23.0 & 5.7 & $1.02 \mathrm{E}-07$ & 7.75E-05 & - \\
\hline 616232 & 11.6 & 4.0 & $3.97 \mathrm{E}-10$ & 3.13E-07 & 4.00 & 2961 & 23.1 & 4.4 & 1.27E-07 & 9.59E-05 & 5.60 \\
\hline 269754 & 11.9 & 8.4 & $1.62 \mathrm{E}-04$ & $1.03 \mathrm{E}-01$ & 8.10 & 65380 & 23.6 & 6.9 & 9.38E-05 & 6.03E-02 & 7.20 \\
\hline 680506 & 12.4 & 5.0 & 4.85E-07 & $3.58 \mathrm{E}-04$ & - & 85700 & 23.7 & 4.7 & 1.18E-08 & $9.20 \mathrm{E}-06$ & 5.98 \\
\hline 58514 & 12.5 & 3.1 & $1.34 \mathrm{E}-08$ & $1.04 \mathrm{E}-05$ & 9.52 & 336628 & 23.7 & 5.9 & 2.62E-07 & 1.97E-04 & 4.77 \\
\hline 353527 & 12.8 & 4.1 & $7.25 \mathrm{E}-07$ & $5.32 \mathrm{E}-04$ & 7.77 & 345647 & 23.8 & 48.5 & 1.03E-05 & 7.09E-03 & 6.59 \\
\hline 106408 & 12.8 & 2.4 & $1.29 \mathrm{E}-06$ & 9.30E-04 & 7.34 & 102811 & 23.9 & 5.3 & 1.99E-08 & $1.54 \mathrm{E}-05$ & 6.96 \\
\hline 620358 & 13.0 & 5.5 & $1.37 \mathrm{E}-05$ & $9.27 \mathrm{E}-03$ & 5.72 & 669356 & 24.5 & 8.1 & 2.09E-06 & 1.49E-03 & 8.00 \\
\hline 65104 & 13.2 & 4.3 & 9.57E-07 & $6.95 \mathrm{E}-04$ & 8.76 & 7521 & 24.5 & 6.9 & 9.49E-05 & $6.08 \mathrm{E}-02$ & 7.52 \\
\hline 325319 & 13.2 & 2.7 & 7.94E-07 & 5.80E-04 & 8.23 & 352876 & 24.7 & 6.7 & 4.35E-05 & 2.86E-02 & 6.27 \\
\hline 328166 & 13.4 & 5.4 & $4.72 \mathrm{E}-07$ & 3.49E-04 & 7.35 & 148958 & 24.9 & 6.9 & 1.03E-07 & 7.81E-05 & 3.09 \\
\hline 658144 & 13.4 & 2.6 & 1.51E-08 & 1.17E-05 & 6.68 & 613009 & 25.0 & 5.7 & 3.89E-06 & $2.75 E-03$ & 7.41 \\
\hline
\end{tabular}

Table 1 List of 136 CSC-inhibitory compounds identified by HTS (\%growth $\leq 50 \%$, p-adj. $\leq 0.1$ ) compared to $\mathrm{Gl}_{50}$ ovCAR-3 cells (Continued) 
Table 1 List of 136 CSC-inhibitory compounds identified by HTS (\%growth $\leq 50 \%$, p-adj. $\leq \mathbf{0 . 1})$ compared to $\mathrm{Gl}_{50}$ of OVCAR-3 cells (Continued)

\begin{tabular}{|c|c|c|c|c|c|c|c|c|c|c|c|}
\hline 10447 & 25.5 & 6.6 & $3.49 \mathrm{E}-07$ & 2.61E-04 & 4.65 & 629971 & 46.5 & 10.7 & $1.01 \mathrm{E}-05$ & $6.96 \mathrm{E}-03$ & 6.54 \\
\hline 301460 & 25.6 & 5.0 & $2.20 \mathrm{E}-06$ & $1.57 \mathrm{E}-03$ & 8.00 & 403883 & 48.3 & 7.0 & 2.37E-05 & 1.57E-02 & 4.00 \\
\hline 605756 & 25.8 & 6.4 & $6.31 \mathrm{E}-07$ & 4.65E-04 & 5.68 & 267033 & 48.5 & 10.9 & 4.31E-05 & 2.84E-02 & 6.35 \\
\hline 407806 & 26.5 & 3.1 & $1.95 \mathrm{E}-06$ & $1.40 \mathrm{E}-03$ & 7.44 & 36437 & 48.5 & 5.5 & 8.51E-06 & 5.91E-03 & 5.23 \\
\hline 67574 & 27.0 & 6.0 & $1.21 \mathrm{E}-06$ & 8.74E-04 & 7.68 & 49842 & 49.1 & 10.6 & $2.34 \mathrm{E}-05$ & $1.56 \mathrm{E}-02$ & 9.71 \\
\hline 700582 & 27.2 & 5.8 & $1.02 \mathrm{E}-07$ & 7.74E-05 & 6.57 & 654259 & 49.8 & 9.0 & 2.57E-06 & $1.83 \mathrm{E}-03$ & 7.23 \\
\hline 304421 & 27.9 & 4.2 & 4.98E-06 & 3.49E-03 & 6.47 & 182986 & 50.1 & 9.1 & $1.52 \mathrm{E}-05$ & $1.02 \mathrm{E}-02$ & 5.27 \\
\hline 521777 & 28.1 & 6.1 & 3.29E-08 & $2.53 \mathrm{E}-05$ & 8.00 & 93739 & 50.4 & 6.5 & $1.54 \mathrm{E}-05$ & $1.04 \mathrm{E}-02$ & 5.40 \\
\hline
\end{tabular}

25510

30297

3341

693632

29.0

4.8

6.10E-07

4.50E-04

6.05

7.02

$24818 \quad 31.0$

$24819 \quad 31.1$

$52141 \quad 31.3$

$96932-31.4$

349155

97911

243928

83265

637993

145669

157930

132791

331757

269142

1906

14229

1620

622627

215989

13973

332598

126727

248436

705330

166454

84074

632841

116693

375575

98904
5.43

7.98

6.44

\section{$10.8 \quad 5.65 \mathrm{E}-05$}

$5.6 \quad 6.80 \mathrm{E}-08$

3.68E-02

5.21E-05

1.58E-04

6.85E-03

8.12

8.47

7.14

6.77

6.45

5.70

5.69

5.70

5.50

7.75

6.16

6.96

5.11

6.68

4.15

5.55

4.00

5.28

1.22E-02

2.07E-03

9.94E-04
Table 1 List of 136 CSC-inhibitory compounds identified by HTS (\%growth $\leq 50 \%$, p-adj. $\leq \mathbf{0 . 1}$ ) compared to $\mathrm{Gl}_{50}$ of OVCAR-3 cells (Continued)

Included among the 793 compounds passing our performance test are 19 drugs previously approved by the FDA for cancer treatment (Table 2). Five of these drugs are among the 136 compounds designated as CSC-inhibitory, but none are commonly used in the treatment of epithelial ovarian cancer. On the other hand, triethylenemelamine (altretamine, NSC9706), which is used for palliative treatment of persistent or recurrent ovarian cancer [30], induced non-significant stimulation of CSC growth in our screening (Table 2).

The two most CSC-inhibitory of the FDA-approved drugs, dactinomycin (NSC 3035; 8.4\% cell growth) [31] and plicamycin (mithramycin A, NSC 24559; 10.8\% cell growth) [32] have both been previously reported to induce programmed cell death or apoptosis by inhibiting RNA transcription. Dactinomycin is used in the treatment of several cancers including gestational trophoblastic neoplasia [33] and Wilms' tumor [34]. Plicamycin has been used in the treatment of testicular cancer [35] and hypercalcemia associated with advanced malignancy [36]. The anti-microtubule drug vincristine (NSC24559) is used in the treatment of acute leukemias, Hodgkin lymphoma, and aggressive non-Hodgkin lymphoma, but is also included in combinations for treatment of small-cell lung cancer, breast cancers and some pediatric neoplasms [37]. Vinblastine (NSC49842) is used in the treatment of Hodgkin's lymphoma [37], and in combination with cisplatin and bleomycin in the treatment of testicular and ovarian germ cell cancers [38]. Mepacrine (quinacrine, NSC14229), an inhibitor of NFkB [39] and topoisomerase activity [40], is primarily used as an antimalarial drug [41]. In oncology, it is most commonly used for the treatment of pleural effusions in advanced malignant diseases [42].

\section{Most ovarian CSC growth-inhibiting compounds also inhibit the growth of more differentiated ovarian cancer cells}

It has been established previously that normal stem cells are more resistant to the induction of apoptosis 


\section{NSC72961}

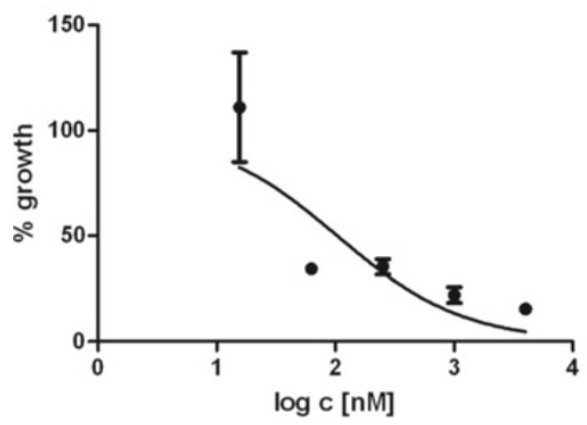

NSC243928

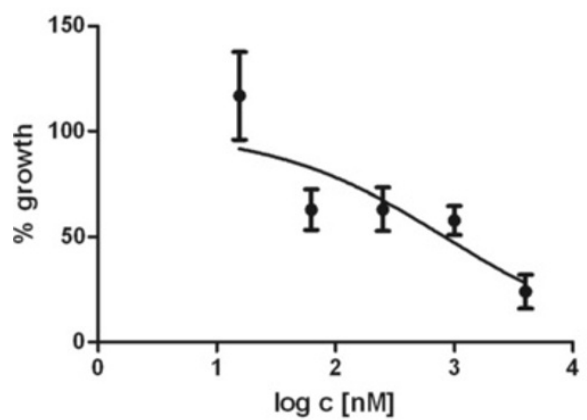

NSC673622

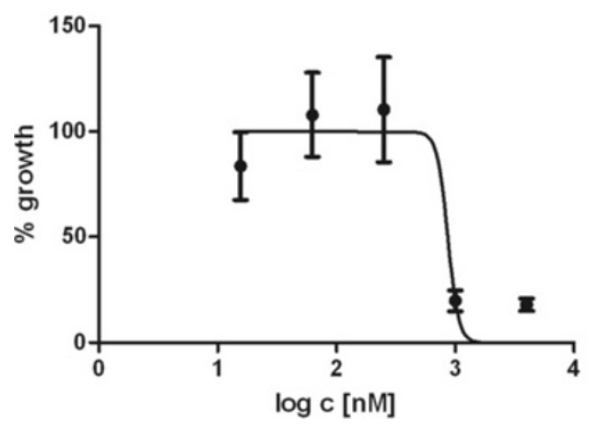

NSC82116

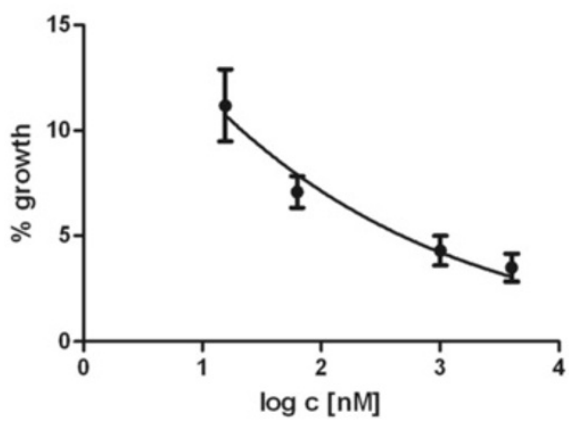

NSC302979

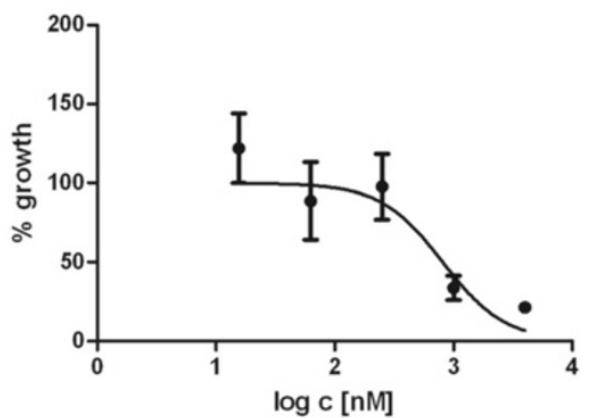

fitted by non-linear regression of log-transformed data using a normalized response-variable slope model. Error bars: SEM.

by radiation and cytotoxic agents than their differentiated progeny and similarly, CSC have been shown to display increased resistance to these same agents relative to the more differentiated cells that comprise the bulk of the tumor [43-45]. Indeed, it has been proposed that this dichotomy may contribute to the recurrence of cancer growth after the initial response of tumors to chemotherapeutic treatments [46]. Consistent with this view, we previously reported that several ovarian cancer drugs (e.g., NSC119875-cisplatin, NSC724770-docetaxel, NSC609699-topotecan) that are effective against ovarian cancer OVCAR-3 cells, are significantly less effective at inhibiting growth of ovarian CSC [13]. To assess if the apparent dichotomy in drug effectiveness between ovarian CSC and their more differentiated progeny is characteristic of the 136 ovarian CSC inhibitory compounds identified in our study, we sought to compare the results of our HTS with NCI's previous testing of compounds against the OVCAR-3 cell line. In the $\mathrm{NCI}$ program, $\mathrm{GI}_{50}$ values (concentrations required to inhibit growth by $50 \%$ ) on OVCAR-3 cells were determined for nearly all of the compounds used in our HTS. The OVCAR-3 GI 50 values (expressed as $-\log _{10} \mathrm{GI}_{50}$ ) for 136 of the CSC-inhibitory compounds are presented in Table 1. The data output from our HTS is relative \% growth rather than $\mathrm{GI}_{50}$ values. However, since the concentration of compounds used in our HTS was $2.29 \mu \mathrm{M}$ (see Methods), the $\mathrm{GI}_{50}$ for compounds resulting in $\leq 50 \%$ growth of CSC is predicted to be $\leq 2.29 \mu \mathrm{M}$ or $\geq 5.64$ on the $-\log _{10}$ scale $\left(-\log _{10} 2.29 \times 10^{-6}=5.64\right)$. By 


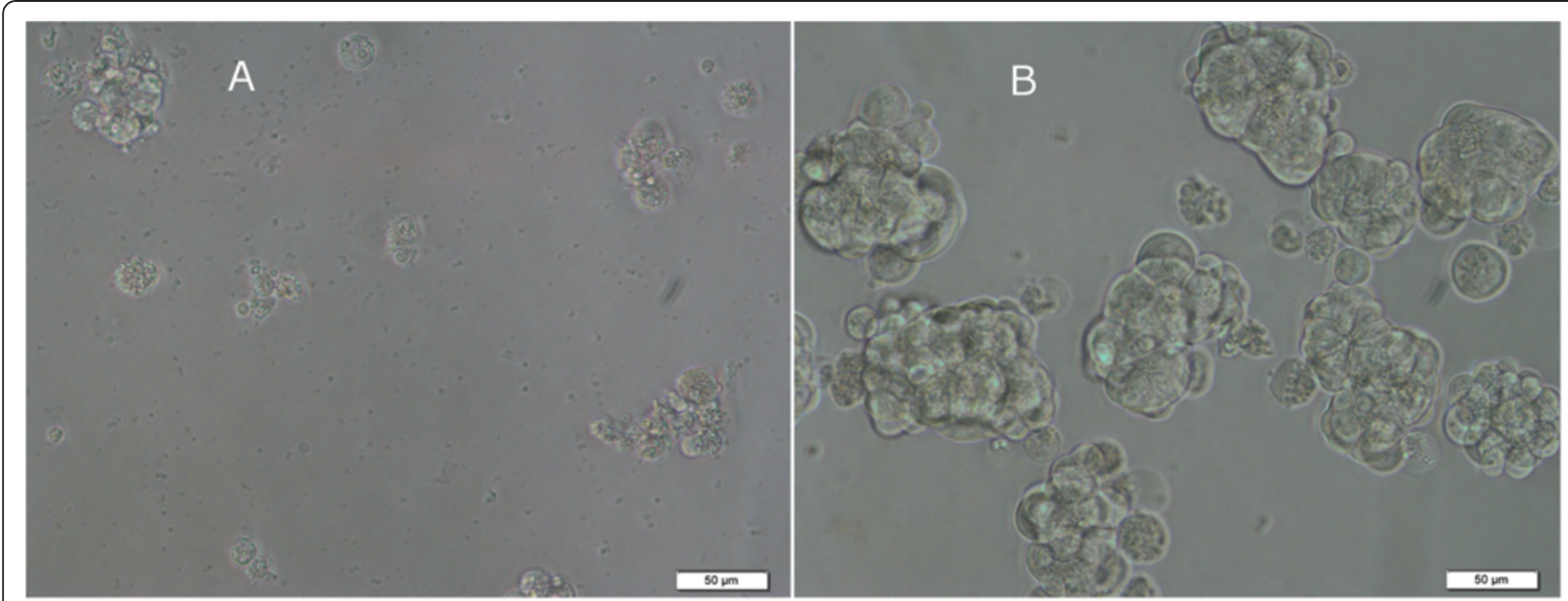

Figure 2 Phenotypic effect of compound NSC72961 (8-azaadenosine) at $4 \mu \mathrm{M}(96 \mathrm{~h}$ ) on ovarian cancer stem-like cell culture. Test treatment $(\mathbf{A})$; solvent control (B). Scale bar $=50 \mu \mathrm{m}$.

comparing this value with the $-\log _{10} \mathrm{GI}_{50}$ values previously determined for OVCAR-3 cells in the NCI study, we found that $73 \%(99 / 136)$ of the compounds that we designated as CSC inhibitory compounds are also inhibitory for OVCAR-3 cells (i.e., $-\log _{10} \mathrm{GI}_{50} \geq 5.64$ ). This suggests that there may be a number of inhibitory compounds with the potential to target both ovarian CSC and their more differentiated progeny. Of the remaining 37 (136-99) CSC-inhibitory compounds, 5 were not previously tested on OVCAR-3. Thus, based on our criteria, we classified 32 compounds to be preferentially inhibitory for CSC (Table 3).

Among the 99 compounds found to be co-inhibitory for CSC and OVAR-3 cells, four have previously been FDA approved for cancer treatment (NSC3053-dactinomycin; NSC24559-plicamycin; NSC49842-vinblastine; NSC67574vincristine) (Table 2). Only one of the previously approved cancer drugs, the NFKB-inhibitor Mepacrine (NSC14229),

Table 2 Results of HTS of CSC with 19 FDA-approved oncology drugs

\begin{tabular}{|c|c|c|c|c|c|c|}
\hline NSC & Name & $\%$ growth & SD (\%) & p-value & p-adj & $\begin{array}{l}\mathrm{Gl}_{50} \text { OVCAR3 } \\
(-\log 10)\end{array}$ \\
\hline 3053 & Dactinomycin & 8.4 & 3.9 & $1.38 \mathrm{E}-08$ & 1.07E-05 & 8.54 \\
\hline 24559 & Plicamycin & 10.8 & 3.6 & $9.91 \mathrm{E}-11$ & 7.86E-08 & 7.35 \\
\hline 67574 & Vincristine & 27.0 & 6.0 & $1.21 \mathrm{E}-06$ & 8.74E-04 & 7.68 \\
\hline 14229 & Mepacrine & 37.6 & 6.1 & $9.93 \mathrm{E}-08$ & $7.56 \mathrm{E}-05$ & 5.55 \\
\hline 49842 & Vinblastine & 49.1 & 10.6 & $2.34 \mathrm{E}-05$ & $1.56 \mathrm{E}-02$ & 9.71 \\
\hline 125066 & Bleomycin & 53.0 & 10.2 & 1.10E-05 & 7.54E-03 & 5.28 \\
\hline 63878 & Cytarabine & 76.6 & 11.0 & $1.04 \mathrm{E}-02$ & 1 & 5.00 \\
\hline 105014 & Cladribine & 82.7 & 17.0 & 7.13E-02 & 1 & 4.59 \\
\hline 755 & Mercaptopurine & 95.2 & 8.4 & $2.83 \mathrm{E}-01$ & 1 & 5.94 \\
\hline 740 & Methotrexate & 96.7 & 30.8 & 8.38E-01 & 1 & 6.69 \\
\hline 226080 & Rapamycin & 97.0 & 20.9 & 7.93E-01 & 1 & 8.17 \\
\hline 296961 & Amifostine & 99.4 & 12.0 & $9.18 \mathrm{E}-01$ & 1 & 3.13 \\
\hline 85998 & Streptozocin & 103.7 & 28.9 & 8.10E-01 & 1 & 3.14 \\
\hline 32065 & Hydroxyurea & 107.4 & 14.8 & $2.38 \mathrm{E}-01$ & 1 & 2.92 \\
\hline 180973 & Tamoxifen & 115.1 & 14.3 & $4.45 \mathrm{E}-02$ & 1 & 5.23 \\
\hline 750 & Busulfan & 120.6 & 15.9 & $3.65 \mathrm{E}-02$ & 1 & 3.60 \\
\hline 38721 & Mitotane & 128.2 & 47.6 & $2.68 \mathrm{E}-01$ & 1 & 4.73 \\
\hline 9706 & Triethylenemelamine & 128.9 & 82.5 & $5.26 \mathrm{E}-01$ & 1 & 4.74 \\
\hline 45388 & Dacarbazine & 164.3 & 14.2 & 4.46E-04 & $2.68 \mathrm{E}-01$ & 4.25 \\
\hline
\end{tabular}


Table 3 Compounds preferentially inhibitory for CSC

\begin{tabular}{|c|c|c|c|c|}
\hline NSC & Name & $\%$ growth & SD & p-adj \\
\hline 618332 & 2,3-Dibromonaphthoquinone & 3.3 & 4.0 & $2.78 \mathrm{E}-04$ \\
\hline 128305 & 5,7-Dihydroxy-3',4'-dimethoxyflavone & 4.9 & 3.4 & $5.59 \mathrm{E}-03$ \\
\hline 636132 & 3-Cyano-N,3-bis(2-methylphenyl)-2-oxopropanamide & 7.3 & 3.2 & $6.89 \mathrm{E}-04$ \\
\hline 622732 & $\mathrm{~N}$-(4-chlorophenyl)-1-methyl-1H-pyrazolo[3,4-b]quinolin-5-amine & 8.0 & 4.9 & $3.46 \mathrm{E}-03$ \\
\hline 208913 & Ethyl 2-(((1-adamantyl(methyl)amino) carbonyl)amino)propanoate & 8.0 & 3.5 & 5.96E-04 \\
\hline 614928 & 3,3,4,4-Tetramethyltetrahydro-2,5-furandiol & 9.3 & 2.0 & $5.56 \mathrm{E}-04$ \\
\hline 667467 & 2-Phenyl-1,4-thiazino[3,2-c]quinoline-3-thione & 9.8 & 3.9 & 2.79E-07 \\
\hline 616232 & Dibromodulcitol & 11.6 & 4.0 & 3.13E-07 \\
\hline 635121 & N'-(1-(4H-1,4-benzothiazin-2-yl)ethylidene)-2-hydroxybenzohydrazide & 16.0 & 5.3 & $6.53 \mathrm{E}-03$ \\
\hline 202000 & (4Z)-4-[(3,4-dichlorophenyl) methylidene]-2-(furan-2-yl)-1,3-oxazol-5-one & 17.7 & 5.0 & $2.38 \mathrm{E}-06$ \\
\hline 629301 & 3,6-Dihydro-3,6-ethanocyclohepta[cd][1]benzofuran-10,10,11,11-tetracarbonitrile & 20.9 & 5.5 & 1.49E-02 \\
\hline 34391 & Cryptocyanine iodide & 22.2 & 4.2 & $3.12 \mathrm{E}-04$ \\
\hline 625483 & 1-(2-Chloro-6-fluorophenyl)-1H,3H-Thiazolo(3,4-a)benzimidazole & 22.8 & 9.7 & 1.68E-02 \\
\hline 72961 & 8-Azaadenosine & 23.1 & 4.4 & 9.59E-05 \\
\hline 336628 & Merbarone & 23.7 & 5.9 & 1.97E-04 \\
\hline 148958 & Ftorafur & 24.9 & 6.9 & 7.81E-05 \\
\hline 10447 & Purpurin & 25.5 & 6.6 & 2.61E-04 \\
\hline 302979 & Shikoccin & 30.4 & 10.8 & $3.68 \mathrm{E}-02$ \\
\hline 637993 & $\begin{array}{l}\text { 6H-Imidazo[4,5,1-de]acridin-6-one, } \\
\text { 5-[2-(diethylamino) ethylamino]-8-methox y-1-methyl-, } \\
\text { dihydrochloride }\end{array}$ & 34.8 & 9.9 & $5.36 \mathrm{E}-02$ \\
\hline 331757 & $\begin{array}{l}\text { 2-Anthracenecarboxamide, } \\
\text { N-[4-(diethylamino)-1-methylbutyl]-9,10-dihydro-9,10-dioxo-, } \\
\text { monohydrochloride }\end{array}$ & 35.6 & 15.4 & $9.84 \mathrm{E}-02$ \\
\hline 1906 & Piperidinium piperidinedithiocarbamate & 36.2 & 3.5 & $3.43 \mathrm{E}-05$ \\
\hline 14229 & Mepacrine & 37.6 & 6.1 & $7.56 \mathrm{E}-05$ \\
\hline 1620 & 4-[[(2-furanyl)methyl]amino]-1H-pyrazolo[3,4-D]pyrimidine & 37.7 & 8.4 & $3.43 \mathrm{E}-03$ \\
\hline 622627 & 2-(chloromethyl)-1,3-dinitro-5-(trifluoromethyl)benzene & 38.4 & 11.4 & $1.22 \mathrm{E}-02$ \\
\hline 248436 & Platinum, dibromo(6-thioguanosine-N7,S6)-, (SP-4-3)- & 41.4 & 9.5 & $9.15 \mathrm{E}-03$ \\
\hline 166454 & Decamine & 41.9 & 7.2 & $6.39 \mathrm{E}-04$ \\
\hline 84074 & Phosphonium, (3-bromopropyl)triphenyl- bromide & 42.9 & 7.3 & $1.23 \mathrm{E}-02$ \\
\hline 116693 & $\begin{array}{l}\text { 2,3-bis(benzoyloxy)succinic acid compound with } \\
\text { 1,4-dimethyl-2-((4-methylphenyl)(phenyl)-I 4-sulfanyl)benzene (1:1) }\end{array}$ & 43.6 & 5.1 & 1.40E-04 \\
\hline 403883 & Cedran-8-ol & 48.3 & 7.0 & 1.57E-02 \\
\hline 36437 & Crassin acetate & 48.5 & 5.5 & $5.91 \mathrm{E}-03$ \\
\hline 182986 & Diaziquone & 50.1 & 9.1 & $1.02 \mathrm{E}-02$ \\
\hline 93739 & Fuchsine & 50.4 & 6.5 & $1.04 \mathrm{E}-02$ \\
\hline
\end{tabular}

is included among those compounds classified as preferentially inhibitory for ovarian CSC (37.6\% growth).

\section{Computational model classifies CSC inhibitory} compounds into predicted cellular response groups

Neither the mode of action nor the molecular targets of the 32 compounds classified by us as preferentially inhibitory for CSC have, as yet, been definitively determined. However, there are a variety of computational tools that can be informative in predicting the putative cellular responses to these compounds and in suggesting lines of future investigation. One such tool, developed by the Covell group at NCI $[27,28,47]$, utilizes data from the treatment of 60 representative human cancer cell lines (the NCI-60 panel) [48] with nearly 30,000 compounds including those investigated 


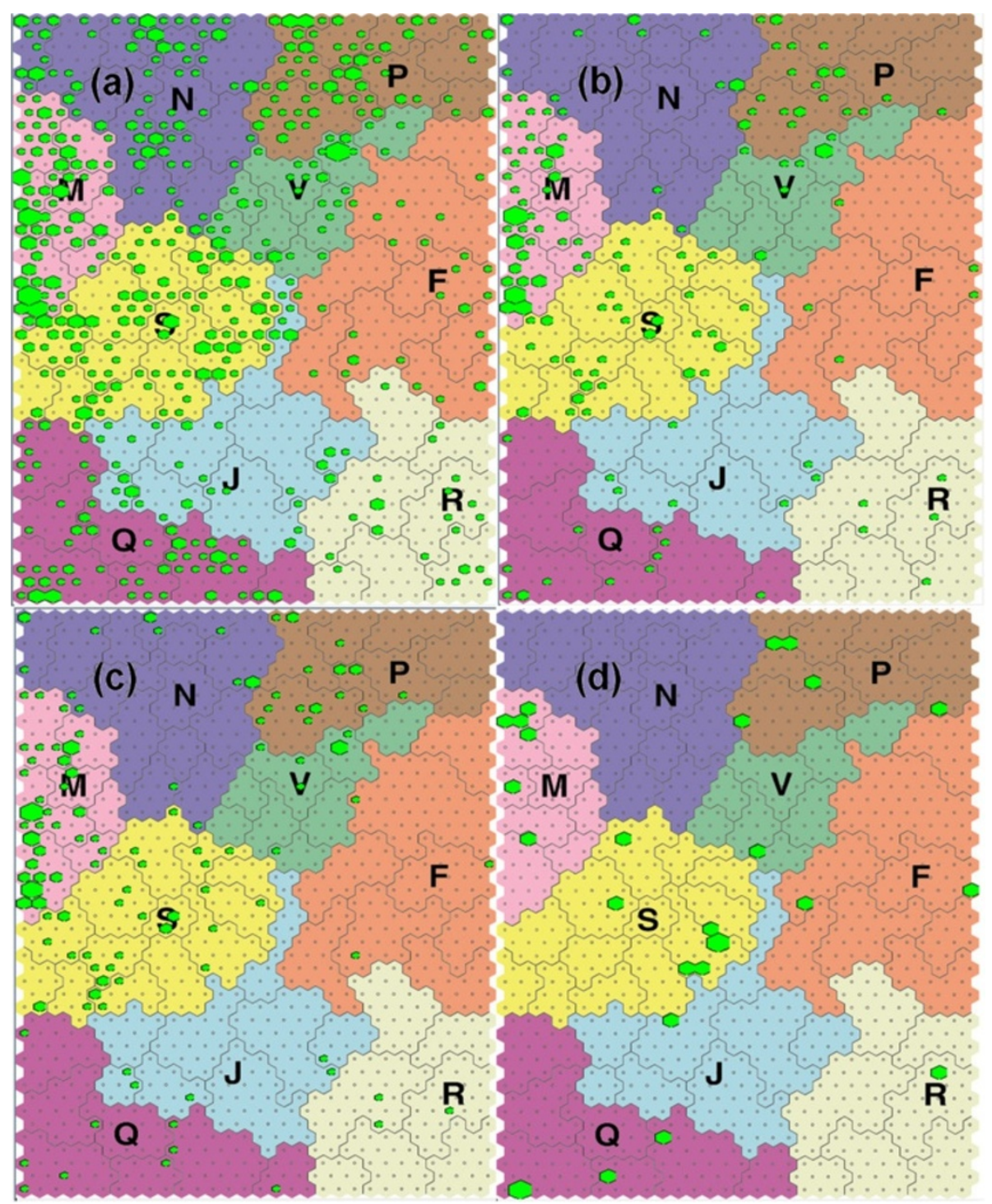

Figure 3 Mapping of compounds used in the HTS onto SOMs. (a) all 793 evaluable compounds (b) 136 CSC inhibitory compounds; (c) 99 CSC and OVCAR-3 co-inhibitory compounds; (d) 32 CSC-specific inhibitory compounds. [mitosis (M), membrane function (N), nucleic acid metabolism (S), metabolic stress and cell survival (Q), kinases/phosphatases and oxidative stress (P) and 4 unexplored regions (RFJV)].

Table 4 Number of compounds mapping into individual cellular response categories of SOM

\begin{tabular}{|c|c|c|c|c|c|c|c|c|c|}
\hline & $\mathrm{F}$ & $\mathrm{J}$ & $M$ & $\mathrm{~N}$ & $\mathbf{P}$ & $\mathbf{Q}$ & $R$ & $S$ & $\mathrm{v}$ \\
\hline (a) & $29(4.2 \%)$ & $44(6.4 \%)$ & $129(18.7 \%)$ & $102(14.8 \%)$ & $92(13.3 \%)$ & $83(12.0 \%)$ & $25(3.6 \%)$ & $140(20.3 \%)$ & $46(6.7 \%)$ \\
\hline (b) & $5(2.6 \%)$ & 7 (3.6\%) & 70 (36.1\%) & $16(8.2 \%)$ & 25 (12.9\%) & $13(6.7 \%)$ & $5(2.6 \%)$ & 42 (21.6\%) & $11(5.7 \%)$ \\
\hline (c) & $3(1.9 \%)$ & $5(3.1 \%)$ & 62 (38.5\%) & 16 (9.9\%) & 19 (11.8\%) & 9 (5.6\%) & $3(1.9 \%)$ & 35 (21.7\%) & $9(5.6 \%)$ \\
\hline (d) & $2(7.4 \%)$ & $1(3.7 \%)$ & $6(22.2 \%)$ & $0(0 \%)$ & $5(18.5 \%)$ & $4(14.8 \%)$ & 1 (3.7\%) & 7 (25.9\%) & $1(3.7 \%)$ \\
\hline$p-a b$ & 0.3988 & 0.1653 & $<0.0001$ & 0.0169 & 1.0000 & 0.0365 & 0.6537 & 0.6882 & 0.7412 \\
\hline p-ac & 0.2469 & 0.1326 & $<0.0001$ & 0.1283 & 0.6970 & 0.0163 & 0.3325 & 0.6663 & 0.7235 \\
\hline p-ad & \multicolumn{9}{|c|}{ Numbers too small for statistical evaluation } \\
\hline
\end{tabular}

(a) all 793 evaluable compounds (b) 136 CSC inhibitory compounds; (c) 99 CSC and OVCAR-3 co-inhibitory compounds; (d) 32 CSC-specific inhibitory compounds. P-values: Fisher's exact test for the significance of differences between proportions of compounds in a given cellular response category in 793 compound set (A) and compound subset $B(p-A B), C(p-A C)$, or $D(p-A D)$. [mitosis $(M)$, membrane function $(N)$, nucleic acid metabolism (S), metabolic stress and cell survival $(Q)$, kinases/phosphatases and oxidative stress $(P)$ and 4 unexplored regions (RFJV)]. 
in our HTS. These data were used to generate a selforganizing map (SOM) that visualizes the position of $\sim 30,000$ screened compounds within 9 major cellular response categories: mitosis $(\mathrm{M})$, membrane function $(\mathrm{N})$, nucleic acid metabolism (S), metabolic stress and cell survival (Q), kinases/phosphatases and oxidative stress (P) and 4 unexplored regions (RFJV).

Using this SOM, we were able to visually compare the predicted cellular responses of all of our screened compounds (that passed assay performance criteria) relative to those identified as having an inhibitory effect on CSC. Shown in Figure 3 is a SOM upon which we have mapped (a) all 793 compounds used in our HTS; (b) the 136 compounds identified as inhibitors of CSC (including compounds that also inhibit OVCAR-3 cells); (c) the 99 compounds identified as co-inhibitory of CSC and OVCAR-3 cells; and (d) the 32 compounds that exert a CSC-specific inhibitory effect.

The results indicate that compared to all 793 evaluable compounds, the 136 identified as inhibitory for CSC are highly significantly enriched for compounds associated with $\mathrm{M}$ (mitotic) cellular responses (M: $36.1 \%$ vs $18.7 \%$; $\mathrm{p}<0.0001$; Figure $3 \mathrm{~b}$ and Table 4 ). This region of SOM contains many compounds known to interfere with microtubule and/or actin filaments, such as taxanes, derivatives of colchicine, vinca alkaloids, rhizoxin and nocodazole [47]. This region also contains compounds associated with inhibition of the DNA polymerase pathway and is associated with the Gene Ontology (GO) terms: Mitotic checkpoint, Cytokinesis, DNA topological change, Cell cycle (Biological Processes); Nucleus, Kinetochore (Cellular Components), and DNA topoisomerase activity (Molecular Function) [28].

The 99 compounds that were co-inhibitory for OVCAR-3 and CSC also displayed a significant enrichment for $M$ cellular responses ( $M$ : $38.5 \%$ vs $18.7 \%$; $\mathrm{p}<0.0001$; Figure $3 \mathrm{c}$ and Table 4). When the 32 compounds classified as preferentially inhibitory for CSC were mapped, the enrichment for $M$ (mitotic) cellular responses was no longer apparent (Figure $3 \mathrm{~d}$ ). Although this may be attributable to the fact that CSC are less mitotically active than cancer epithelial cells [43], the relatively small number of compounds (32) in this category precludes definitive conclusions.

\section{Conclusion}

We tested the inhibitory effect of 825 compounds (NCI Mechanistic Set) on the growth of ovarian CSC derived from a previously established epithelial ovarian cancer cell line (OVCAR-3) [13]. 158 of these compounds were found to have a significant inhibitory effect on ovarian CSC growth. The most inhibitory of these compounds ( $\leq 50 \%$ growth relative to controls) were designated as CSC inhibitory. Among these 136 CSC inhibitory compounds are 5 FDA-approved cancer drugs, but none of these are commonly used in the treatment of epithelial ovarian cancer. A comparison of the ovarian CSC inhibitory compounds identified in this study with compounds previously shown to be inhibitory for OVCAR-3 ovarian cancer cells revealed an unexpected $73 \%$ overlap. Computational analysis indicates that the majority of these compounds are associated with mitotic cellular responses.

While epithelial ovarian cancer is frequently responsive to current chemotherapeutic treatments, disease recurrence remains a persistent problem that has been, at least partially, attributed to the fact that ovarian CSC are resistant to standard therapies [6,13]. Our HTS has uncovered a number of candidate compounds that may, after further testing, prove effective in targeting both ovarian CSC and their more differentiated progeny.

\section{Additional files}

Additional file 1: Plate design, assay performance evaluation and systematic error detection doc.

Additional file 2: 97 drugs from the FDA-approved oncology drug set, Description: NSC - NSC identifier; CAS - CAS identifier.

Additional file 3: Compounds from the 2 plates failing the assay performance test, Description: AP - Assay plate \#; NSC - NSC identifier; \%growth; SD - standard deviation of \%growth; p-value determined by Welch's $t$-test between treated and control wells.

Additional file 4: Results of HTS for 793 compounds that passed the assay performance test (also shown are GI50 values $(-\log 10)$ for OVCAR-3 cells), Description: AP - Assay Plate; NSC - NSC identifier; \%growth; SD - standard deviation of \%growth; p-value determined by Welch's $t$-test between treated and control wells; rank - rank of compound according to $\mathrm{p}$-value; $\mathrm{p}$-adj_Holms Holm's procedure-adjusted p-values; position - position of drug in assay plate; OVCAR-3 - GI50 values for OVCAR-3 cell line (retrieved from $\mathrm{DTP} / \mathrm{NCl})$.

\section{Abbreviations}

CSC: Cancer Stem Cells; DTP: Developmental Therapeutics Program;

FDA: U.S. Food and Drug Administration; HTS: High Throughput Screening; NCl: National Cancer Institute; NSC: National Service Center; SOM: Self-Organizing Map.

\section{Competing interests}

All authors declare that they have no competing interests.

\section{Authors' contributions}

RM and JM conceived the study and wrote the manuscript. RM and LW performed the HTS experiment. RM processed and analyzed the data. All authors read and approved the final manuscript.

\section{Acknowledgements}

Authors thank Dr. David G. Covell (National Cancer Institute - Frederick) for his assistance with accessing the 3D Mind tool, Vinay K. Mittal (Georgia Institute of Technology) for his help with data processing and the Developmental Therapeutics Program of $\mathrm{NCl}$ for providing the $\mathrm{NCl}$ Mechanistic Set library. The Deborah Nash Harris Endowment Fund and the Robinson Family Foundation provided support for this project.

Received: 5 September 2012 Accepted: 13 October 2012

Published: 18 October 2012 


\section{References}

1. Jemal A, Siegel R, Xu J, Ward E: Cancer statistics, 2010. CA Cancer J Clin 2010, 60:277-300.

2. Herzog TJ: Recurrent ovarian cancer: how important is it to treat to disease progression? Clin Cancer Res 2004, 10:7439-7449.

3. Bapat SA, Mali AM, Koppikar CB, Kurrey NK: Stem and progenitor-like cells contribute to the aggressive behavior of human epithelial ovarian cancer. Cancer Res 2005, 65:3025-3029.

4. Zhang S, Balch C, Chan MW, Lai HC, Matei D, Schilder JM, Yan PS, Huang TH, Nephew KP: Identification and characterization of ovarian cancer-initiating cells from primary human tumors. Cancer Res 2008, 68:4311-4320.

5. Baba T, Convery PA, Matsumura N, Whitaker RS, Kondoh E, Perry T, Huang Z, Bentley RC, Mori S, Fujii S, Marks JR, Berchuck A, Murphy SK: Epigenetic regulation of CD133 and tumorigenicity of CD133+ ovarian cancer cells. Oncogene 2009, 28:209-218.

6. Alvero AB, Chen R, Fu HH, Montagna M, Schwartz PE, Rutherford T, Silasi DA, Steffensen KD, Waldstrom M, Visintin I, Mor G: Molecular phenotyping of human ovarian cancer stem cells unravels the mechanisms for repair and chemoresistance. Cell Cycle 2009, 8:158-166.

7. Ginestier C, Charafe-Jauffret E, Birnbaum D: Targeting breast cancer stem cells: fishing season open! Breast Cancer Res 2010, 12:312.

8. McDermott SP, Wicha MS: Targeting breast cancer stem cells. Mol Oncol 2010, 4:404-419.

9. Clayton S, Mousa SA: Therapeutics formulated to target cancer stem cells: is it in our future? Cancer Cell Int 2011, 11:7.

10. Gupta PB, Onder TT, Jiang G, Tao K, Kuperwasser C, Weinberg RA, Lander ES: Identification of selective inhibitors of cancer stem cells by highthroughput screening. Cell 2009, 138:645-659.

11. Pollard SM, Yoshikawa K, Clarke ID, Danovi D, Stricker S, Russell R, Bayani J, Head R, Lee M, Bernstein M, Squire JA, Smith A, Dirks P: Glioma stem cell lines expanded in adherent culture have tumor-specific phenotypes and are suitable for chemical and genetic screens. Cell Stem Cell 2009, 4:568-580.

12. Visnyei K, Onodera H, Damoiseaux R, Saigusa K, Petrosyan S, De Vries D, Ferrari D, Saxe J, Panosyan EH, Masterman-Smith M, Mottahedeh J, Bradley KA, Huang J, Sabatti C, Nakano I, Kornblum HI: A molecular screening approach to identify and characterize inhibitors of glioblastoma stem cells. Mol Cancer Ther 2011, 10:1818-1828.

13. Wang L, Mezencev R, Bowen NJ, Matyunina LV, McDonald JF: Isolation and characterization of stem-like cells from a human ovarian cancer cell line. Mol Cell Biochem 2011, 363:257-268.

14. Al-Hajj M, Wicha MS, Benito-Hernandez A, Morrison SJ, Clarke MF: Prospective identification of tumorigenic breast cancer cells. Proc Natl Acad Sci USA 2003, 100:3983-3988.

15. Singh SK, Hawkins C, Clarke ID, Squire JA, Bayani J, Hide T, Henkelman RM Cusimano MD, Dirks PB: Identification of human brain tumour initiating cells. Nature 2004, 432:396-401

16. Levina V, Marrangoni AM, De Marco R, Gorelik E, Lokshin AE: Drug-selected human lung cancer stem cells: cytokine network, tumorigenic and metastatic properties. PLoS One 2008, 3:e3077.

17. Ginestier C, Hur MH, Charafe-Jauffret E, Monville F, Dutcher J, Brown M, Jacquemier J, Viens P, Kleer CG, Liu S, Schott A, Hayes D, Birnbaum D, Wicha MS, Dontu G: ALDH1 is a marker of normal and malignant human mammary stem cells and a predictor of poor clinical outcome. Cell Stem Cell 2007, 1:555-567.

18. Holbeck SL: Update on $\mathrm{NCl}$ in vitro drug screen utilities. Eur J Cancer 2004, 40:785-793.

19. Mechanistic set information; http://dtp.nci.nih.gov/branches/dscb/ mechanistic_explanation.html.

20. DTP basic chemical data search; http://dtp.nci.nih.gov/dtpstandard/ ChemData/index.jsp.

21. Hsiao AY-C: $3 D$ spheroid culture systems for metastatic prostate cancer dormancy studies and anti-cancer therapeutics development. Universtiy of Michigan: (Doctoral dissertation). Retrieved from ProQuest Dissertations \& Theses (ID 896131060); 2011.

22. Dong Y, Tan OL, Loessner D, Stephens C, Walpole C, Boyle GM, Parsons PG Clements JA: Kallikrein-related peptidase 7 promotes multicellular aggregation via the alpha(5)beta(1) integrin pathway and paclitaxel chemoresistance in serous epithelial ovarian carcinoma. Cancer Res 2010, 70:2624-2633.
23. Inglese J, Shamu CE, Guy RK: Reporting data from high-throughput screening of small-molecule libraries. Nat Chem Biol 2007, 3:438-441.

24. Holm S: A simple sequentially rejective multiple test procedure. Scand J Statist 1979, 6:65-70.

25. Approved Oncology Drugs Set Information: A set of FDA-approved anticancer drugs to enable cancer research; http://dtp.cancer.gov/branches/dscb/ oncology_drugset_explanation.html.

26. DTP; http://dtp.nci.nih.gov.

27. 3D MIND; http://spheroid.ncifcrf.gov/spheroid/

28. Huang R, Wallqvist A, Thanki N, Covell DG: Linking pathway gene expressions to the growth inhibition response from the National Cancer Institute's anticancer screen and drug mechanism of action. Pharmacogenomics J 2005, 5(6):381-399.

29. Text document with names; http://dtpsearch.ncifcrf.gov/ OPEN NAMES FEB03.TXT.

30. Wiernik PH, Yeap B, Vogl SE, Kaplan BH, Comis RL, Falkson G, Davis TE, Fazzini $\mathrm{E}$, Cheuvart B, Horton J: Hexamethylmelamine and low or moderate dose cisplatin with or without pyridoxine for treatment of advanced ovarian carcinoma: a study of the Eastern Cooperative Oncology Group. Cancer Invest 1992, 10:1-9.

31. Fraschini $A$, Bottone MG, Scovassi Al, Denegri M, Risueño MC, Testillano PS, Martin TE, Biggiogera $M$, Pellicciari C: Changes in extranucleolar transcription during actinomycin D-induced apoptosis. Histol Histopathol 2005, 20:107-117.

32. Lee TJ, Jung EM, Lee JT, Kim S, Park JW, Choi KS, Kwon TK: Mithramycin A sensitizes cancer cells to TRAIL-mediated apoptosis by down-regulation of XIAP gene promoter through Sp1 sites. Mol Cancer Ther 2006 5:2737-2746

33. Lewis JL Jr: Chemotherapy of gestational choriocarcinoma. Cancer 1972 30:1517-1521.

34. Frei E 3rd: The clinical use of actinomycin. Cancer Chemother Rep 1974 $58: 49-54$

35. Kennedy BJ: Mithramycin therapy in advanced testicular neoplasms. Cancer 1970, 26:755-766.

36. Perlia CP, Gubisch NJ, Wolter J, Edelberg D, Dederick MM, Taylor SG 3rd: Mithramycin treatment of hypercalcemia. Cancer 1970, 25:389-394.

37. Pratt WB, Ruddon RW, Ensminger WD, Maybaum J: The anticancer drugs. 2nd edition. New York: Oxford University Press; 1994

38. Gershenson DM, Morris M, Cangir A, Kavanagh JJ, Stringer CA, Edwards CL, Silva EG, Wharton JT: Treatment of malignant germ cell tumors of the ovary with bleomycin, etoposide, and cisplatin. J Clin Oncol 1990, 8:715-720.

39. Gurova KV, Hill JE, Guo C, Prokvolit A, Burdelya LG, Samoylova E, Khodyakova AV, Ganapathi R, Ganapathi M, Tararova ND, Bosykh D, Lvovskiy D, Webb TR, Stark GR, Gudkov AV: Small molecules that reactivate p53 in renal cell carcinoma reveal a NF-kappaB-dependent mechanism of p53 suppression in tumors. Proc Natl Acad Sci USA 2005, 102:17448-17453.

40. Preet R, Mohapatra P, Mohanty S, Sahu SK, Choudhuri T, Wyatt MD, Kundu CN: Quinacrine has anticancer activity in breast cancer cells through inhibition of topoisomerase activity. Int J Cancer 2012, 130(7):1660-1670.

41. Van Dyke K, Lantz C, Szustkiewicz C: Quinacrine: mechanisms of antimalarial action. Science 1970, 169:492-493.

42. Koldsland S, Svennevig JL, Lehne G, Johnson E: Chemical pleurodesis in malignant pleural effusions: a randomised prospective study of mepacrine versus bleomycin. Thorax 1993, 48:790-793.

43. Diehn M, Clarke MF: Cancer stem cells and radiotherapy: new insights into tumor radioresistance. J Natl Cancer Inst 2006, 98:1755-1757.

44. Dean M, Fojo T, Bates S: Tumour stem cells and drug resistance. Nat Rev Cancer 2005, 5:275-284.

45. Wicha MS, Liu S, Dontu G: Cancer stem cells: an old idea-a paradigm shift. Cancer Res 2006, 66:1883-1890.

46. Lobo NA, Shimono Y, Qian D, Clarke MF: The biology of cancer stem cells. Annu Rev Cell Dev Biol 2007, 23:675-699.

47. Rabow AA, Shoemaker RH, Sausville EA, Covell DG: Mining the National Cancer Institute's tumor-screening database: identification of compounds with similar cellular activities. J Med Chem 2002, 45:818-840.

48. Shoemaker $\mathrm{RH}$ : The $\mathrm{NCl} 60$ human tumour cell line anticancer drug screen. Nat Rev Cancer 2006, 6:813-823.

doi:10.1186/1757-2215-5-30

Cite this article as: Mezencev et al:: Identification of inhibitors of ovarian cancer stem-like cells by high-throughput screening. Journal of Ovarian Research 2012 5:30. 